\title{
Entrelacs
}

Cinéma et audiovisuel

$8 \mid 2011$

Imaginaire

\section{Guy Debord, de son cinéma en son art et son temps}

\section{Guy Chapouillié}

\section{OpenEdition}

Journals

Édition électronique

URL : http://journals.openedition.org/entrelacs/246

DOI : $10.4000 /$ entrelacs.246

ISSN : 2261-5482

Éditeur

Éditions Téraèdre

Édition imprimée

Date de publication : 1 février 2011

ISBN : 978-2-360850-03-7

ISSN : 1266-7188

\section{Référence électronique}

Guy Chapouillié, «Guy Debord, de son cinéma en son art et son temps », Entrelacs [En ligne], 8 | 2011, mis en ligne le 01 août 2012, consulté le 21 septembre 2020. URL : http://journals.openedition.org/ entrelacs/246 ; DOI : https://doi.org/10.4000/entrelacs.246

Ce document a été généré automatiquement le 21 septembre 2020.

Tous droits réservés 


\title{
Guy Debord, de son cinéma en son art et son temps
}

\author{
Guy Chapouillié
}

\section{RÉFÉRENCE}

Guy Claude Marie

Guy Debord, de son cinéma en son art et son temps

Relié : 224 pages

Editeur : VRIN - 2010

ISBN : 978-2711622214

Prix : $16 €$

1 Je ne sais pas si je l'ai lu au meilleur de moi-même, mais, à la fin de ce livre, je suis sûr d'une chose, c'est que si le cinéma n'appartient à personne, sinon à ceux qui l'aiment, alors, Guy Claude Marie aime le cinéma.

2 Le cinéma de la protestation contre l'économie marchande que caractérisent le spectaculaire concentré, le spectaculaire diffus, le spectaculaire intériorisé ; contre toute religion de la marchandise qui laisse entrevoir l'éloignement de la vie, aux limites de la dévastation.

3 Il aime le cinéma de l'écoute fertile des différences et des sujets chers à Guy Debord : celui de l'examen historique, de la théorie, des essais, de la mémoire.

4 En s'engageant dans ce chantier, Guy Claude Marie n'a pas visé l'artifice du productivisme ; il a choisi comme chemin de recherche celui déjà tracé par Guy Debord, "à reprendre depuis le début ", toujours ; un chemin qui réclame du temps pour relire, refaire, critiquer, corriger et blâmer ; relire et refaire et par conséquent refaire aussi Guy Claude Marie, le transformer, le détourner, ultime des sagesses. Un chemin précieux à l'heure où, d'après Peter Lawrence professeur à Cambridge, « le principal résultat de la bibliométrie, c'est que l'objectif majeur des savants n'est plus de faire des 
découvertes mais de publier autant que possible, de sorte que l'utilité, la qualité et l'objectivité des articles se sont dégradées "...

5 En effet, ça se lit, Guy Claude Marie a su prendre le temps de voir les films, de les montrer et d'en discuter, de découvrir le scénario Debord, de croiser le tout, de reprendre au début et puis de rendre une somme inachevée, certes, mais incandescente. Et si, en 2009, les Archives Debord ont été déclarées «Trésor national », il ne fait aucun doute que ce livre en fait désormais partie avec son lot de questions nouvelles. De sorte qu'il n'est pas abusif de dire que Guy Claude Marie est un rebelle et un bel aventurier puisque, pour Guy Debord, l'aventurier c'est celui qui fait arriver des aventures plus que celui à qui les aventures arrivent.

Un livre qui rappelle que, dans notre époque de décomposition singulière, où tout est fait pour endormir, avec des spécialistes de la méthode Coué qui chaque matin, chaque jour, viennent servir leurs doses quotidiennes de suggestion, il est salutaire de ne pas oublier Guy Debord et de se recharger auprès de sa pensée en cinéma, de Hurlements en faveur de Sade à Guy Debord, son art et son temps (Sept films au total).

« Nous ne sommes pas sur cette planète pour quelque chose. Le tout est de passer le temps, ce n'est déjà pas très facile. Tous les moyens employés, poésie, action, amours, laissent un drôle de goût dans la bouche. C'est pourtant ce que nous avons de mieux. Il faut donc s'opposer à tout ce qui limite leur utilisation. C'est pourquoi l'action et l'écriture n'ont de valeurs que libératrices. C'est pour cela que j'ai dit que le poète doit être un incendiaire et je le maintiens... »

7 Ce livre enflammé plaide en faveur d'une guerre de la liberté qui doit être faite avec colère, quitte à lancer contre cette société dix fois de suite ou davantage, des assauts d'une importance comparable à celui de mai 1968, des assauts de qualités diverses, y compris et surtout des films. Car la lecture nous rappelle que tout est toujours à reprendre depuis le début.

8 En tout cas, c'est le livre engagé d'un amateur, amoureux des premiers temps, puisque Guy Claude Marie parle de sa rencontre avec l'œuvre de Guy Debord dès l'âge de 20 ans; une découverte vécue comme un doux trauma qu'il a digéré progressivement jusqu'à la production de ce livre écrit avec une sincérité et une modestie singulières qui caractérisent la qualité d'un chantier large et profond su $r$ l'œuvre d'un inventeur redoutable, docteur en rien, certes, mais toujours capable en tout, puisque le livre montre à quel point les films de Guy Debord insistent, persistent et résistent de manière irrésistible à l'instar de Hurlements en faveur de Sade qui ouvre toujours des brèches esthétiques et politiques, avec fluidité et de manière tranchante, jusqu'à faire hurler de bonheur Guy Claude Marie.

9 C'est un fait, Guy Debord voulait parler la belle langue de son siècle, en quête d'un éclat égal à celui de la foudre zébrant le paysage, le paysage en cinéma. Et bien, le livre foisonne de ces zébrures qui ont produit des bouleversements de situations et l'émergence de formes autonomes où le son n'est pas un son synchrone, ni asynchrone mais l'entrelacs de sons et d'images d'où émerge l'image audiovisuelle dans le fracas d'une incohérence tonique et singulièrement productive pour le détournement.

$10 \mathrm{Au}$ total, ça palpite entre la finesse de l'analy se des films de Guy Debord et le dévoilement de l'amour de Guy Debord pour une certaine qualité du cinéma en général, au point où les morceaux de films détournés ressemblent aussi à des aveux de bonheur (p. 127-129 Johnny Guitar). Des aveux qui n'entament nullement l'objet du détournement puisque pour Guy Claude Marie, les fragments détournés gardent leur grâce tout en 
changeant de poids ce qui place l'importance de Guy Debord, non pas dans la négation du cinéma mais dans son enrichissement, son émancipation, jusqu'à faire de son cinéma une œuvre théorique et poétique ; c'est là toute l'entreprise de Guy Debord qui a toujours considéré le cinéma comme propice à la plus grande beauté du détournement. Du détournement, non comme une négation du style mais comme le style de la négation.

11 Alors, si pour Guy Debord, l'engagement poétique et révolutionnaire "c'est son caractère ». Qu'il me soit permis de saluer ici le caractère poétique et protestataire de Guy Claude Marie qui, au bout d'un engagement qui n'a jamais faibli, projette un intervalle de clarté sur une œuvre cinématographique majeure.

\section{AUTEURS}

\section{GUY CHAPOUILLIÉ}

Professeur émérite à l'Université de Toulouse II le Mirail / ESAV 